\title{
INDUSTRIAL RECYCLE TOWARDS ZERO DISCHARGE - Alumina Refinery Case Study
}

\author{
Quamie N. Mortley ${ }^{1}$, Winston A. Mellowes ${ }^{2}$ \\ ${ }^{1}$ Chemical Engineering and Energy Consultant, Kingston, Jamaica \\ ${ }^{2}$ Faculty of Engineering, The University of the West Indies, Trinidad \\ ${ }^{1}$ Email: qnmortley@yahoo.com \\ ${ }^{2}$ Email:wamello@yahoo.com
}

\begin{abstract}
Water management at alumina refineries and associated power plants is a major concern, especially if water resources are scarce and liquid discharges are not permitted. This paper describes the case of one such plant in Jamaica recovering $350 \mathrm{~m}^{3} / \mathrm{h}$ of digester regenerative condensate. The steam and power for the alumina refinery is supplied by a cogeneration facility, which has to use a mix of well water and return condensate from the steam users in the alumina production process. The refinery produces alumina from Jamaican bauxite ore, using the Bayer process. This process includes the digestion of bauxite with sodium hydroxide at 135 deg.C, hence the requirement for both steam and power. In the course of this extraction, large quantities $\left(350 \mathrm{~m}^{3} / \mathrm{h}\right)$ of digester and evaporator condensate are produced. In view of the limited liquid discharges permitted from the site, this condensate was stored on site in large ponds, and reused in the process. Pressured from three sides, with a limitation on raw water abstraction from the wells by the Water Resource Authority, a requirement for minimized liquid discharge of wastewater, and high cost of energy there was a need to utilize the regenerative condensate from the digesters and the evaporators as boiler feedwater. Studies carried out by international water treatment companies had concluded that Total Organic Carbon (TOC) would not allow condensate re-use as boiler feedwater, with an attached US\$10 million cost for the removal of TOC. Extensive laboratory work and thermodynamic analysis were carried out and the condensate are used as boiler feedwater, without treatment. The avoided cost was US $\$ 10$ million and energy savings of US\$3 million realized.
\end{abstract}

Keywords: alumina refinery, water management, liquid discharge, condensate https://doi.org/10.47412/PBFD4932

\section{Introduction}

The Alumina refinery produces alumina from bauxite ore, using the Bayer process. This process includes the digestion of bauxite with sodium hydroxide at 135 deg.C, hence the requirement for both steam and power. In the course of this extraction, large quantities $\left(>350 \mathrm{~m}^{3} / \mathrm{h}\right)$ of digester condensate are produced. This condensate is cooled, neutralized and discharged from the site to the environment.

Pressured from three sides, with a limitation on raw water abstraction from the wells by the Water Resource Authority, a requirement for minimized liquid discharge of wastewater, and high cost of energy there was a need to utilize the regenerative condensate from the digesters and the evaporators as boiler feedwater. Studies carried out by three international water treatment companies had concluded that Total Organic Carbon (TOC) would not allow condensate re-use as boiler feedwater, with an attached US\$10 million cost for the removal of TOC. 
The capital outlay for treating the digester regenerative condensate would add about $\$ 15 / \mathrm{t}$ to the production cost of alumina, in a market where the price of alumina was been depressed for the past 6 years. Given the required capital outlay for treating water and condensate contaminated with organics, a new approach was required. An engineering approach was used.

\subsection{Thermodynamic Modelling of Hydrometallurgical Processes}

This area examines the physical properties of Bayer process liquors with respect to thermodynamic modelling. The partioning of organic material between liquor and condensate will determine how much and nature of organic species in condensate.

Thermodynamic modelling of hydrometallurgical processes [1] is usually focused on optimizing product yield. However, large numbers of inorganic and organic impurities enter process streams during the acidic or alkaline leaching of the ore. Since impurities tend to build up, especially when plant liquors are recycled, control strategies usually aim to achieve a steady state of impurity concentrations by balancing process inputs and outputs. However, the problems arising from impurities are often compounded because the impurities may be transformed by a variety of chemical and redox reactions, form precipitates or volatile compounds. Impurities frequently affect the physicochemical properties of the liquor, including important process parameters such as densities, heat capacities, and viscosities. They often interfere with process performance: for instance, precipitates may form scale or co-crystallize with the product. Improved thermodynamic modelling capabilities that allow robust predictions for multi component aqueous systems containing numerous electrolytes and nonelectrolytes at small to medium concentrations are therefore required. This area of study include the partitioning of volatile compounds among process liquors, steam and condensates in a train of flash vessels, the development of thermodynamically consistent models for organic impurities in Bayer liquors, and the prediction of their mixing properties with major liquor components.

\section{Organic Impurities in the Bayer Process - Volatile Organic Compounds}

\subsection{Organic compounds in the Bayer Process}

The chemistry of "organics" in Bayer liquors is extremely complex. Organic compounds enter the process through the bauxite ore, which contains woody material (lignin, cellulose, hemicellulose) and humic substances. The latter originate from plant and animal material transformed by oxidative (decomposition) and reductive (resynthesis) humification processes [2] during geochemical ore formation. The harsh conditions prevailing during bauxite digestion result in degradation of the organic material contained in the ore. Different types of ore and different conditions during the digestion stage of the Bayer process thus lead to different distributions of organics in Bayer liquors. The redox potential of the liquor during digestion is negative enough to form hydrogen, methane, ammonia, metallic mercury, and various volatile organic compounds (VOCs) [3]. While many VOCs are short-lived due to their high reactivity, a number of volatiles (including mercury) are released during flash cooling and/or dissolve in the digestion condensate. This leads to certain environmental issues, which can be compounded because the condensate is used for washing or dilution throughout the refinery. The partitioning of various classes of volatile substances among liquor, steam, and condensate has been successfully modeled within the framework of the existing Bayer liquor model. As mentioned above, the organic macromolecules extracted from the two main carbon sources in bauxite (partly) decompose in hot Bayer liquors. The primary low-molecular-weight products are benzenecarboxylates, phenolates, and aliphatic carboxylates.

Organic impurities are known to affect the physicochemical properties of the liquor, including density and heat capacity. 
Fig. 1 shows a schematic representation of the Bayer process, which also indicates possible problems caused by the formation of volatile organic compounds (VOCs).

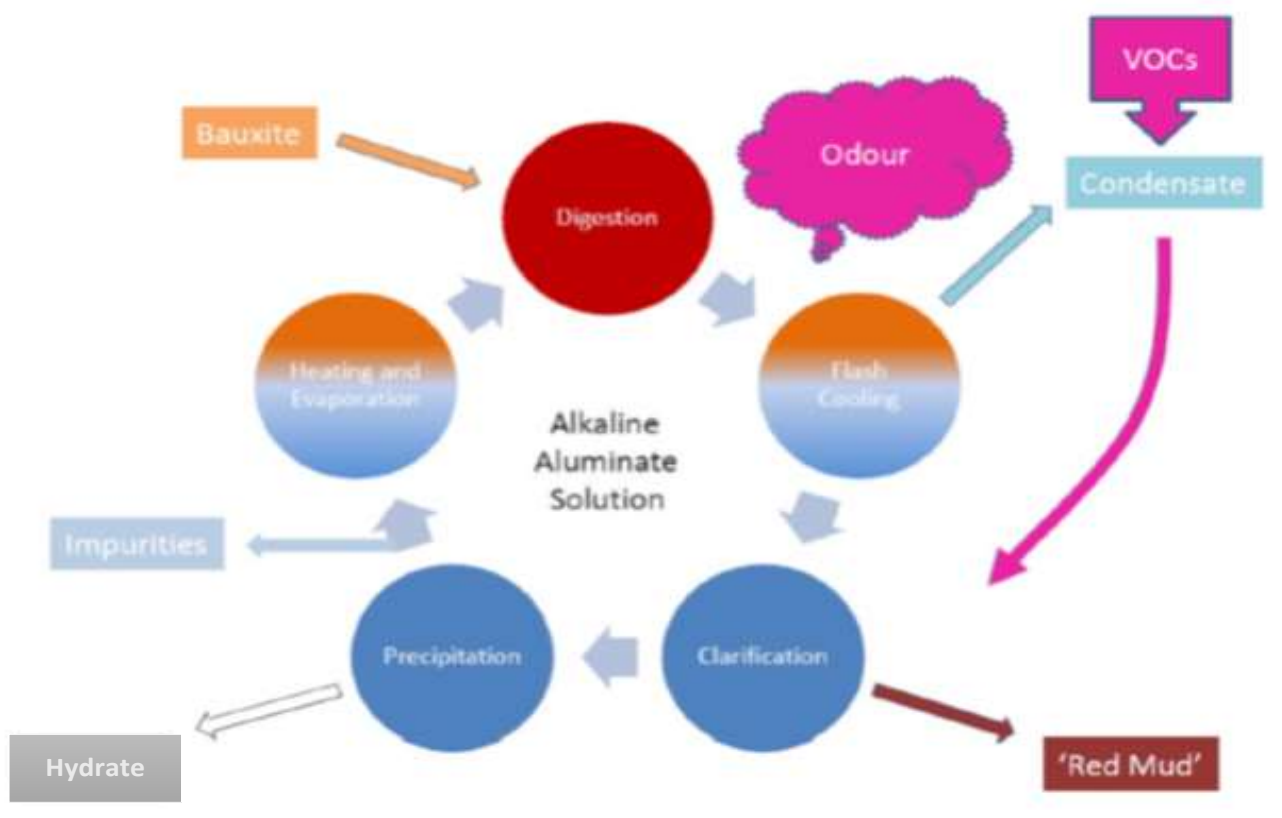

Figure 1: Schematic of the Bayer process.

Impurities entering at the digestion stage are partly removed from the liquor stream as solids leaving with "red mud" (essentially iron hydroxides and other solid phases precipitated from the alkaline process liquor). Soluble impurities are controlled by appropriate treatment of side streams, which are discharged, e.g., after the precipitation stage. Typically, VOCs are formed during digestion. They may lead to odor problems, but can also be transported to other parts of the refinery since they partly dissolve in digestion condensates, which are often used for washing solid waste ("red mud") and hydrate.

Fig. 2 shows a schematic of the digester train showing vapour from the digester flash tanks being condensed to give rise to the digester regenerative condensate.

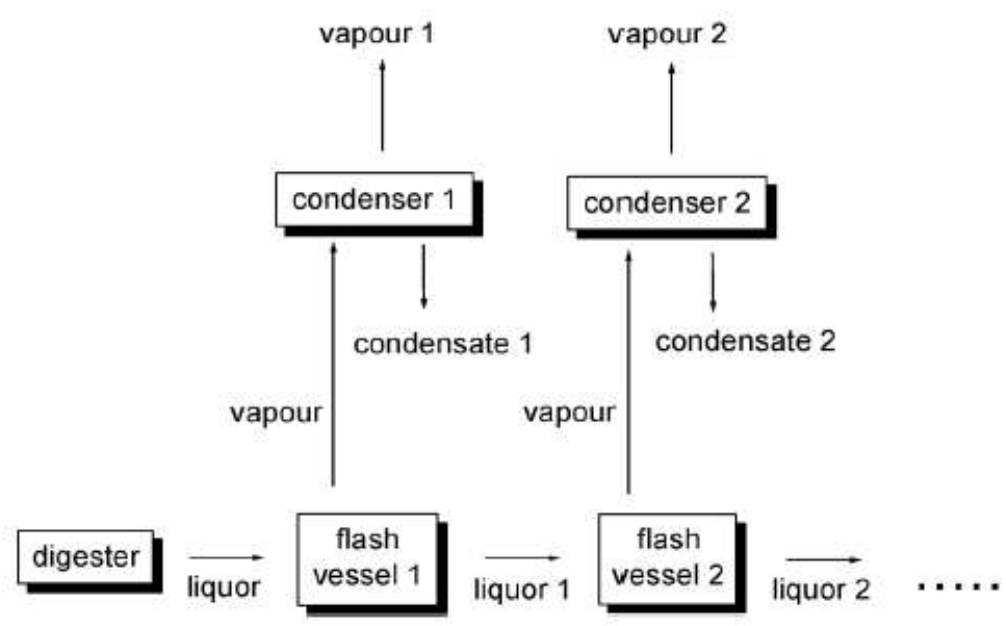


Figure 2: Thermodynamic simulation of a train consisting of flash vessels and condensers in a Bayer plant.

The liquor enters the first flash vessel from the digester, passes through the subsequent flash vessels operating at successively lower pressures, and is eventually cooled down to boiling temperature at atmospheric pressure.

Fig. 3 shows the distribution of selected volatiles among the various phases. Since absolute concentrations of volatile compounds are in general unavailable, relative values (percentages), are shown. These refer to a trace amount of each volatile leaving the digester as species dissolved in the liquor, which is taken as 100 $\%$. Generally, the distribution of trace amounts of volatiles between aqueous and vapour phases depend on the relative amounts of the two phases. For the flash tanks, these amounts are calculated assuming adiabatic expansion. The resulting relative liquor composition as shown in Fig. 3, were then taken as input to the next flash tank. The relative vapour compositions obtained from flashing were the inputs to the corresponding condensers/heat exchangers shown in Fig. 2.

The important deduction is that as the liquor enters the first flash vessel from the digester, passes through the subsequent flash vessels operating at successively lower pressures, the distribution of organics in the condensate is reduced to zero as the liquor progresses down the flash train.
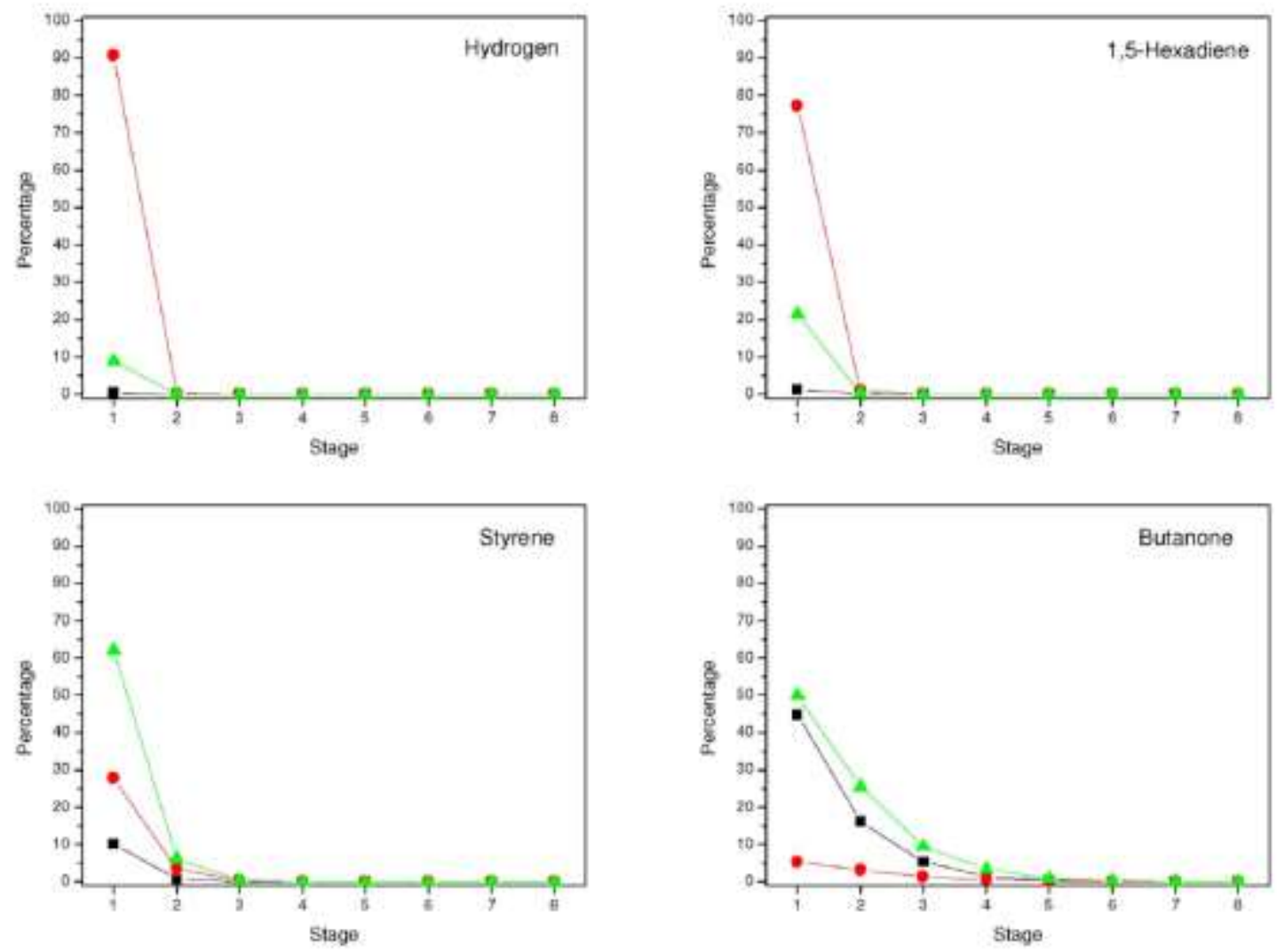

Figure 3: Relative amounts of selected volatiles in liquor $(\boldsymbol{\bullet})$, steam $(\bullet)$, and condensate $(\Delta)$ from thermodynamic simulations of a train of flash vessels in a Bayer plant.

Hydrophobic solutes like $\mathrm{H}_{2}$ and aliphatic hydrocarbons are virtually completely removed from the liquor in the first flash vessel, where they can be destroyed by thermal oxidation. Aromatic compounds, such as styrene, dissolve significantly in the first condensate and will be partly released on cooling and reducing 
the pressure. On the other hand, more hydrophilic substances like aldehydes, ketones, alcohols, and amines dissolve in the aqueous phases to much higher extents, and are consequently being transported down the train of flash vessels.

\section{Condensate Quality}

Total Organic Carbon (TOC) is a measure of organic material contamination in the water. TOC is a direct measure of the oxidizable organic material. Organics can break down to form acids that lower the boiler $\mathrm{pH}$ and can also cause foaming in boiler drums resulting in boiler water carryover with steam. The digester condensate chemical analysis is shown in Table 1 [4]. It was determined that there was no oily matter in the condensate and that the organics present would be removed at the deaerator. As a precaution, cationic conductivity was done on the boiler feedwater to determine the presence of acid forming species.

Table 1: Digester Condensate Chemical Analysis

\begin{tabular}{|l|l|l|l|l|l|}
\hline Constituents & Units & Digester 1 & Digester 2 & BFW & $\begin{array}{l}\text { Boiler } \\
\text { Water }\end{array}$ \\
\hline pH & Units & 10.3 & 10.3 & & \\
\hline Conductivity & $\mu \mathrm{mhos}$ & 166 & 112 & & $\leq 3800$ \\
\hline P Alkalinity & $\mathrm{mg} / \mathrm{l}$ & 159 & 147 & & \\
\hline M Alkalinity & $\mathrm{mg} / \mathrm{l}$ & 215 & 187 & & \\
\hline Sulphur & $\mathrm{mg} / \mathrm{l}$ & $<0.5$ & $<0.5$ & & \\
\hline Chloride & $\mathrm{mg} / \mathrm{l}$ & 0.5 & 0.5 & & \\
\hline Calcium & $\mathrm{mg} / \mathrm{l}$ & 0.02 & 0.13 & & \\
\hline Magnesium & $\mathrm{mg} / \mathrm{l}$ & $<0.1$ & 0.1 & & \\
\hline Total Hardness & $\mathrm{mg} / \mathrm{l}$ & $<0.02$ & 0.13 & $\leq 0.2$ & \\
\hline Copper & $\mathrm{mg} / \mathrm{l}$ & $<0.002$ & 0.002 & $\leq 0.2$ & \\
\hline Iron & $\mathrm{mg} / \mathrm{l}$ & $<0.002$ & 0.014 & $\leq 0.03$ & \\
\hline Sodium & $\mathrm{mg} / \mathrm{l}$ & 14.4 & 0.9 & & \\
\hline Phosphate & $\mathrm{mg} / \mathrm{l}$ & $<0.4$ & $<0.4$ & & \\
\hline Silica & $\mathrm{mg} / \mathrm{l}$ & 0.11 & 0.07 & & $\leq 40$ \\
\hline Ammonia - Free & $\mathrm{mg} / \mathrm{l}$ & 46 & 40 & & \\
\hline Aluminum & $\mathrm{mg} / \mathrm{l}$ & 0.6 & 0.7 & & \\
\hline Oily Matter & $\mathrm{mg} / \mathrm{l}$ & 0.0 & 0.0 & $\leq 0.5$ & \\
\hline Non-Volatile TOC & $\mathrm{mg} / \mathrm{l}$ & & & $\leq 0.5$ & \\
\hline TOC & $\mathrm{mg} / \mathrm{l}$ & 57 & 44 & & \\
\hline
\end{tabular}

\section{Digestion Regenerative Condensate Heat Value}

During the test period, the condensate at 88 deg.C replaced $90 \mathrm{t} / \mathrm{h}$ of treated water at 25 deg.C for fuel savings of $15 \mathrm{t}$ HFO per day. The savings at the time was $\$ 3,000,000$. A new condensate recovery system was commissioned.

\section{Conclusion}

An engineering solution for a water treatment problem, using thermodynamic modelling of hydrometallurgical process resulted in an avoided treatment cost of US $\$ 10,000,000$ for digester regenerative condensate and an energy saving of US $\$ 3,000,000$. 


\section{References}

[1] Konigsberger, E. 2010. Thermodynamics of Impurities in Hydrometallurgical Processes, $14^{\text {th }}$ International Symposium on Solubility Phenomena and Related Equilibrium Processes, Leoben, Austria, (25-30 July 2010).

[2] Clapp, C.E, Hayes, M.H.B. Sizes and Shapes of Humic Substances, Soil Science 164 (1999).

[3] Mullett, M., et al. Removal of Mercury from an Alumina Refinery Aqueous Stream, Journal of Hazardous Materials, 144 (2007).

[4] Personal communication with GE Betz (now Suez Water Management), Trevose, Pennsylvania, United States, who carried out the water analyses. 